\title{
siRNA quelling of tri4 and tri5 genes related to deoxynivalenol synthesis in Fusarium graminearum and Fusarium culmorum
}

\begin{tabular}{lll}
\hline Paper received: 06.06.2018 Revised received: $14.11 .2018 \quad$ Revised received: 07.12 .2018 \\
\hline
\end{tabular}

\section{Authors Info \\ E. Yörük ${ }^{1}$ and G. Albayrak ${ }^{2 *}$ \\ ${ }^{1}$ Institute of Science, Programme of Molecular Biology and Genetics, Istanbul University, \\ Istanbul, 34134, Turkey \\ ${ }^{2}$ Department of Molecular Biology and Genetics, Faculty of Science, Istanbul University, \\ Istanbul, 34134, Turkey}

*Corresponding Author Email : gulruh@istanbul.edu.tr

\section{Edited by \\ Dr. Sumati Gaumat}
Reviewed by
Dr. R.B. Raizada
Dr. Gangadhar Barlaya

\section{Abstract}

Aim : This study was conducted to investigate the quelling of tri4 and tri5 genes associated with deoxynivalenol, most common class B trichothecene, via siRNAapplication.

Methodology : In this study, one Fusarium graminearum (4F) and two F. culmorum (9F and 20F) isolates, expressing high levels of tri4 and tri5 genes, were targeted for siRNA-based silencing. Full length tri4 and tri5 genes were amplified from all isolates, sequenced and then subjected to CLUSTALW analysis for designing siRNA molecules. Totally designed six siRNAs were separately co-transfected together with helper plasmids (pEGFP75 and pAN7-1) as 36 combinations into protoplast cultures and quelling was analysed via real time polymerase chain reaction, thin layer chromatography and spectrofluorimetric analysis.

Results : Alignment of both tri4 and tri5 genes' sequencing revealed high levels of similarity between isolates ( $94-99 \%$ and $95-100 \%$, respectively). Transfection efficiency ranged from $50 \pm 0.00 / 5 \times 10^{4}$ to $99.33 \pm 10.06 / 5 \times 10^{4}$ and relative fluorescence unit values were calculated between $1.37 \pm 0.07$ and $2.89 \pm 0.06$. The $0.7 \mathrm{~kb}$ length fragments of $h p h$ and GFP were amplified from transfectants. The real time PCR revealed that tri4 was completely suppressed in 30 experimental sets whereas downregulations of tri5, ranging from 74.5 to $99 \%$, was detected in remaining 6 experiment groups. Thin layer chromatography assay also showed

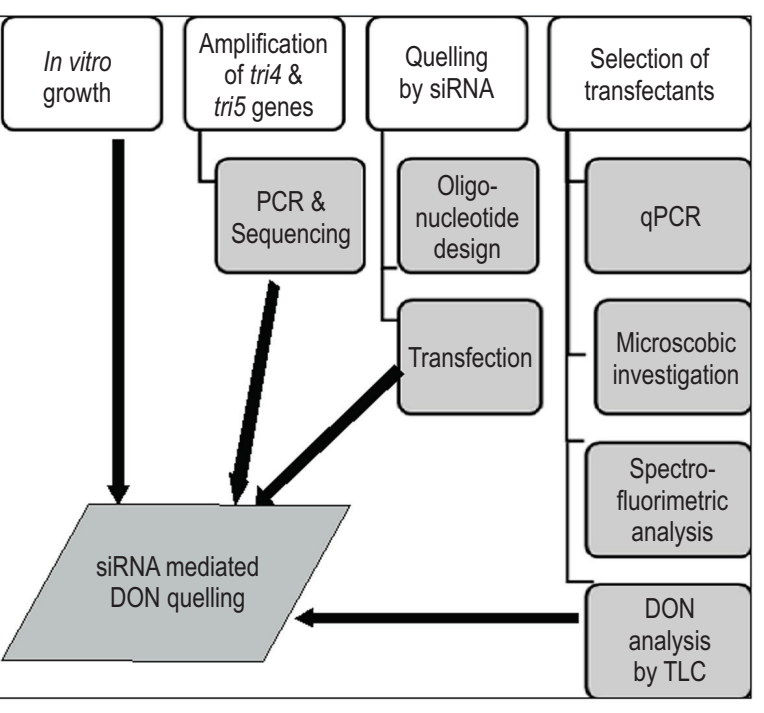
that siRNA-transfected Fusarium samples showed no deoxynivalenol spots.

Interpretation : This study revealed that tri4 and tri5 genes can be targeted in the development of less deoxynivalenol (DON)-producing strains through RNAi. Moreover, current study has great importance as it demonstrates that quelling can be used as a potential strategy in controlling diseases caused by phytopathogenic species.

Key words: Fusarium sp., Gene expression, Gene silencing, Transfection, Trichothecene

How to cite : Yörük E. and G. Albayrak : siRNA quelling of tri4 and tri5 genes related to deoxynivalenol synthesis in Fusarium graminearum and Fusarium culmorum. J. Environ. Biol., 40, 370-376 (2019). 


\section{Introduction}

Quelling is the post transcriptional gene silencing mechanism in fungi (Ruvkun, 2001; Thakur, 2003). RNA interference (RNAi) based gene silencing is responsible for antiviral defence in several Ascomycota species such as Neurospora crassa, Aspergillus niger and Fusarium culmorum. RNAi process is elicited by noncoding double stranded short (20$25 \mathrm{nt}$ ) interfering RNAs (siRNA). Direct transfection of synthetic siRNA molecules to fungal cells is a powerful approach for genetic manipulations although vector-based silencing is well accepted strategy in gene silencing including quelling (Barnes et al., 2008; Nakayashiki and Nguyen, 2008; Scherm et al., 2011). However, application of siRNA transfection is not common in fungi.

Endotoxins produced by fungi are composed of diverse group of chemical substances. Geographic and climate differences affect the mycotoxin types and their production levels. These chemical substances occur in raw agricultural products both preand post-harvested (Kuiper-Goodman, 2004). Therefore, mycotoxins and food safety will continue to be of critical interest to researchers (Battilani et al., 2008). Fusarium spp. produces several types of mycotoxins, including class-B trichothecenes (Desjardins and Proctor, 2007). Deoxynivalenol (DON) is the most accumulated class-B trichothecene on cereals, including barley (Hordeum vulgare), maize (Zea mays) and wheat (Triticum aestivum). Since DON is transported into dopaminergic receptors in human brain after consumption of food contaminated with mycotoxin, it is also named as vomitoxin (Sobrova et al., 2010; Matny, 2015). DON is a sesquiterpenoid structured secondary metabolite.

Toxins decrease crop yield quality and quantity in agriculture. High level of DON shows acute toxic effect in humans and livestock animals. This phytotoxin has a stable structure under high temperatures and during food processing (Desjardins and Proctor, 2007; Sobrova et al., 2010). Trichothecene biosynthetic pathway has been defined in $F$. graminearum and $F$. sporotrichioides strains (Brown et al., 2004; Kimura et al., 2007). Farnesyl pyrophosphate is the start metabolite, and various enzymes and transcription factors coded by tri5 gene cluster are functional in the DON production (Kimura et al., 2007). Several genes in tri5 gene cluster - including tri6, tri5 and tri4 are strongly conserved in distinct trichothecene types and cluster genes expressions are essential in trichothecene production. However, some genes show variation in point of number, size and functionality. DON producers contain tri7 and tri13 genes as deleted and/or disrupted, therefore they are non-functional genes in the pathway (Brown et al., 2004).

The tri5 and tri4 genes located in tri5 gene cluster are essential in DON biosynthesis. Tri5 is the first gene identified in trichothecene biosynthetic pathway. The gene is 1179 bp length, contains one intron and encodes trichodiene synthase (TR/5) which converts farnesyl pyrophosphate to trichodiene. Tri4 is 1741 bp length including three introns, and codes a multifunctional monooxygenase (TR/4). The amino acid sequence of TRI4 is highly similar to cytochrome P450. Tri4 protein catalysis the conversion of trichodiene to isotrichotriol (Kimura et al., 2007). Alterations in media ingredients including magnesium or ferulic acid addition, $\mathrm{H}_{2} \mathrm{O}_{2}$ treatment, acidic $\mathrm{pH}$ supply, etc. have been used as strategy in decreasing DON production in culture conditions (Merhej et al., 2010; PinsonGadias et al., 2008). In field, fungicide treatment is the only way to reduce of Fusarium spp. reproduction and the amount of their related toxins (Kang et al., 2001). However, since fungal strains may develop resistance to certain antimicrobials, it needs to be in development of additional and new disease control strategies (Kimura et al., 2007; Leeja and Thoppil, 2007). It is also thought that the development of less mycotoxin producing strains through genetic engineering strategies may be more effective in the struggle with pathogens and their toxins.

Gene silencing technology has been reported to be a useful tool for eliminating mycotoxin contaminated food products and aggressiveness of mycotoxigenic pathogens (McDonald et al., 2005; Scherm et al., 2011). In view of this, this study was carried out to study silence of both tri4 and tri5 genes through RNAi-based strategy in order to develop less DON-producing strains.

\section{Materials and Methods}

Growth conditions and determination of hygromycin B resistance of fungal strains: Fungal spores of $F$. graminearum isolate $4 \mathrm{~F}$ and $F$. culmorum isolate 20F were obtained from barley kernels while F. culmorum 9F spores were obtained from diseased wheat samples from Turkey. Fungal strains were grown on potato dextrose agar and potato dextrose broth in a light and dark cycle at $25^{\circ} \mathrm{C}$ for seven days. Fungal liquid cultures were incubated by shaking at $160 \mathrm{rpm}$. Fungal isolates were grown on both PDA and PDB mediums containing 25, 50, 75 and $100 \mu \mathrm{g} \mathrm{ml}^{-1}$ hygromycin B for assessing antibiotic susceptibility. Minimum inhibitory concentration (MIC) and half-maximal (50\%) inhibitory concentration $\left(\mathrm{IC}_{50}\right)$ of hygromycin $\mathrm{B}$ were determined through agar dilution technique and spectrophotometric analysis (at OD600).

Nucleic acids isolation and cDNA synthesis: Genomic DNAs and total RNAs were extracted from seven-day-old fungal cultures and quelling samples. Genomic DNAs were isolated from $50 \mathrm{mg}$ fresh weight mycelia through CTAB-based protocol of Doyle and Doyle (1987) with minor modifications. TriPure reagent (Roche, Switzerland) was used in total RNA extraction from $1 \mathrm{ml}$ liquid culture or $50 \mathrm{mg}$ fresh weight mycelia according to manufacturer's recommendation. Components for cDNA synthesis were mixed in a reaction volume of $25 \mu$ l containing: $1 \mathrm{U}$ transcript or HF reverse transcriptase, $1 \mu \mathrm{g}$ total RNA, $60 \mu \mathrm{M}$ random hexamer, $1 \mathrm{X}$ reaction buffer, $5 \mu \mathrm{M}$ DTT, $1 \mathrm{U}$ protector RNase inhibitor and $1 \mathrm{mM}$ dNTPs. The synthesis reaction was performed through thermal steps as follows: $65^{\circ} \mathrm{C}$ for $10 \mathrm{~min}$, $55^{\circ} \mathrm{C}$ for $30 \mathrm{~min}$ and $85^{\circ} \mathrm{C}$ for $5 \mathrm{~min}$. In cDNA synthesis, primer annealing was carried out at $65^{\circ} \mathrm{C}$ for $10 \mathrm{~min}$ and then $\mathrm{RNase} \mathrm{H}$ activity and reverse transcription were maintained by incubation steps at $55^{\circ} \mathrm{C}$ for $30 \mathrm{~min}$ and $85^{\circ} \mathrm{C}$ for $5 \mathrm{~min}$. 
Amplification and sequencing of tri4 and tri5 genes: Each of tri4 and tri5 genes was aligned via ClustalW analysis in output deposited at GenBank with AY102584, AY102605, AY102603, AY102602, AY102571 and AY102571 accession numbers. Then, consensus regions were used for designing specific primer pairs. Full length tri4 and tri5 amplifications of $4 \mathrm{~F}, 20 \mathrm{~F}$ and $9 \mathrm{~F}$ isolates were carried out by PCR in $25 \mu$ reaction volume including $1 X$ PCR buffer, $2.5 \mathrm{mM} \mathrm{MgCl}_{2}, 0.2 \mathrm{mM}$ each dNTP, 10 pmol of each primer, $1 \mathrm{U}$ Taq DNA polymerase (Promega, USA) and $50 \mathrm{ng}$ of DNA. PCR amplification was performed by pre-denaturation at $95^{\circ} \mathrm{C}$ for $5 \mathrm{~min}$, followed by 35 cycles of amplification at $95^{\circ} \mathrm{C}$ for $45 \mathrm{sec}, 55-60^{\circ} \mathrm{C}$ for $45 \mathrm{sec}, 72^{\circ} \mathrm{C}$ for $2 \mathrm{~min}$ and final extension at $72^{\circ} \mathrm{C}$ for $5 \mathrm{~min}$. PCR bands were separated on $1.5 \%$ agarose gels and visualized by gel documentation system. Amplification products belonging to tri4 (1741 bp) and tri5 (1187 bp) genes were purified by using a commercial kit (Roche, Switzerland) and then separately cloned into $E$. coli DH5a strain using pGEM T-Easy cloning system (Promega, U.S.A.) according to the manufacturer's instruction. Plasmids were isolated from recombinant bacterial clones using commercial plasmid isolation kit (Invitrogen, U.S.A.), and were sequenced based on Sanger dideoxy chain termination method. Nucleotide sequences were aligned via Chromas Lite Edition and then assembled by using DNA Dragon software. Total sequences of tri4 and tri5 genes were deposited in GenBank.

Quelling through siRNA: Multiple sequence alignment analysis was carried out in the sequences belonging to two exon regions of tri5 and four regions of tri4 genes. Totally 6 synthetic double stranded siRNAs were designed through Perfectlt siRNA design tool (Invitrogen, U.S.A.) according to sequence showing 100\% homology with reference sequences AY102584, AY102605, AY102603, AY102602, AY102571 and AY102571 accession numbers (Table 1). The plasmid constructs pEGFP (containing gfpgene) and pAN7-1 (containing hph gene) were used in the cotransfection of Fusarium protoplasts with siRNAs. Protoplasts were obtained from mycelia after enzymatic digestion of cell walls by lytic enzyme (Sigma, Germany) with $20 \mathrm{mg} \mathrm{ml}^{-1}$ final concentration. The cultures were incubated at $25^{\circ} \mathrm{C}$ by shaking $160 \mathrm{rpm}$ for $6 \mathrm{hrs}$. Two volume of STC buffer (20\% sucrose, 25 $\mathrm{mM}$ Tris- $\mathrm{HCl}, \mathrm{pH} 7.5,25 \mathrm{mM} \mathrm{CaCl}_{2}$ ) was added to filtrate and samples were centrifugated at $800 \mathrm{xg}$ for $10 \mathrm{~min}$. Protoplasts were diluted to final concentrations of $5 \times 104$. Protoplasts were transfected with plasmid vector (pAN 7-1 or pEGFP75) and siRNA molecules. $1 \mu \mathrm{g}$ plasmid DNA, $150 \mathrm{pmol}$ of siRNA and $1 \mathrm{X}$ transfection reagent (Roche, Switzerland) were mixed in a microtube and incubated at room temperature for $15 \mathrm{~min}$. Then the mixture was transferred to PDB medium immediately.

Mycelia obtained from seven-day-old transfectants were visualized in fluorescence microscopy (Leica, Germany). Spectro fluorometric measurements were carried out at 485/535 nm excitation/emission wavelengths, and relative fluorescence unit values were calculated. Co-transformants were also verified through PCR assays. GFPF/GFPR and HYGBF/HYGBR primers were used for producing of GFP $(720$ bp region) and hygromycin $B$ resistance gene (707 bp length region), respectively. PCR conditions were carried out as described previously in tri4 and tri5 amplification.

Gene expressions and DON analysis in transfectants: Tri4 and tri5 primer and probe sets were designed using primer3 software and universal probe library online services (Roche, Switzerland). Real time PCR (qPCR) assays were performed in LightCycler 480 II system (Roche, Switzerland) using Taq-Man probes. qPCRs were conducted in a volume of $20 \mu$ containing: 2 $\mu \mathrm{l}$ CDNA, $1 \mathrm{X}$ probe master mix (Roche, Switzerland), $2 \mathrm{pmol}$ probe and $4 \mathrm{pmol}$ of primers. Cycling conditions consist of 45 cycles; followed by at $95^{\circ} \mathrm{C}$ for $10 \mathrm{sec}$, at $60^{\circ} \mathrm{C}$ for $30 \mathrm{sec}$, at $72^{\circ} \mathrm{C}$ for $1 \mathrm{sec}$. The slope values were calculated by standard series with a range of four dilutions. Mean crossing point $(\Sigma C p)$ and $\Delta C p$ values were recorded. Target gene expression level was normalized according to $\beta$-tubulin and $2^{-\Delta C T}$ values were determined via formula developed by Livak and Schmittgen (2001).

Reverse transcription PCR (RT-PCR) assays were performed in order to confirm QPCR findings. RT-PCRs were conducted on $25 \mu$ volume including; 1x PCR buffer, $2.5 \mathrm{mM}$ $\mathrm{MgCl}_{2}, 0.2 \mathrm{mM}$ each dNTP, 5 pmol primer, $1 \mathrm{U}$ of Taq DNA polymerase (Promega, USA) and cDNA corresponding to $1 \mu \mathrm{g}$ total RNA. The cycling conditions were performed at $94^{\circ} \mathrm{C}$ for 2 min for pre-denaturation, 35 cycles at $94^{\circ} \mathrm{C}$ for $30 \mathrm{sec}, 58^{\circ} \mathrm{C}$ for 30 $\mathrm{sec}, 72^{\circ} \mathrm{C}$ for $30 \mathrm{sec}$ and $72^{\circ} \mathrm{C}$ for $2 \mathrm{~min}$ for final extension. RTPCR bands were analysed as described before. The GPCR and RT-PCR analysis were replicated at least three times for each experimental set.

Thin layer chromatography (TLC) was used in order to determine DON mycotoxin both in seven-day-old control sets and co-transfectants. For this, $5 \mathrm{ml}$ of fungal cultures were filtrated by double gauze. Ethyl acetate of $1 / 5$ volume was added to filtrate and samples were mixed thoroughly. After centrifugation at 5000 $\mathrm{xg}$, for $5 \mathrm{~min}\left(+4^{\circ} \mathrm{C}\right)$, ethyl acetate was removed. Samples were dried and then dissolved with acetonitrile. In TLC, silica gel $60 F_{254}$ (Merck, Germany), ethyl acetate:toluene (1:1) and ethanol:aluminium chloride (99:1) were used as adsorbent, solvent.) The mycotoxin samples were co-spotted together with trichothecene standard (Sigma, Germany) on silica gels, then run for 45-60 min. Silica gels were sprayed with reactive, and Rf value was calculated via visualization at $365 \mathrm{~nm}$ UV light.

\section{Results and Discussion}

Fungal isolates showed no growth in in vitro for each concentration of hygromycin B. The MIC and IC ${ }_{50}$ values of $4 F, 9 F$ and $20 \mathrm{~F}$ isolates were determined as $25 \mathrm{\mu g} \mathrm{ml}^{-1}$ and $12.5 \mathrm{\mu g} \mathrm{ml}^{-1}$ hygromycin B, respectively. All fungal isolates were highly sensitive to hygromycin B. Double stranded siRNAs were designed according to tri4 and tri5 nucleotide sequences which belonged to $4 \mathrm{~F}, 20 \mathrm{~F}$ and $9 \mathrm{~F}$ isolates. Amplification products of $1187 \mathrm{bp}$-length of tri5, were obtained from $4 \mathrm{~F}$ and $9 \mathrm{~F}$, and that of 1741 bp-length of tri4, were obtained from 4F and 20F (Fig. 1 A). 

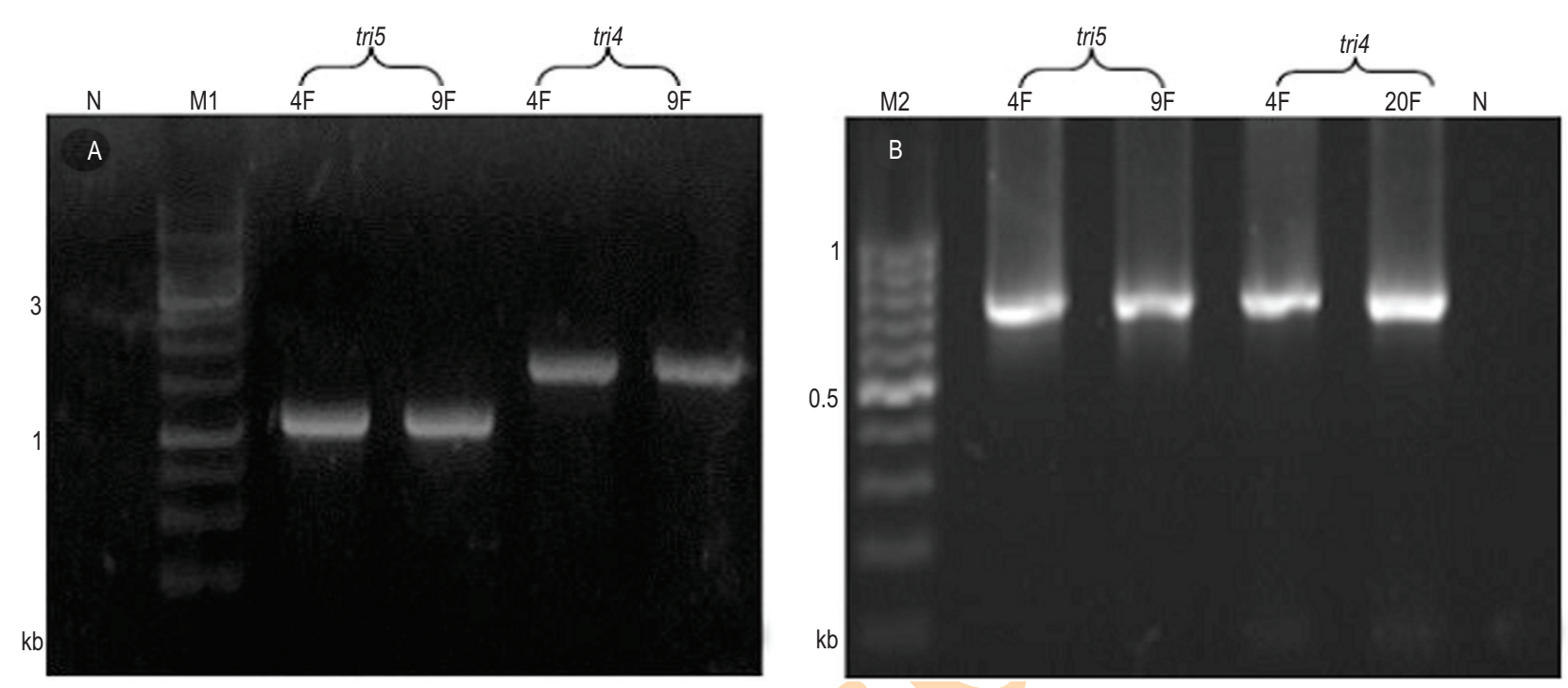

Fig. 1: (A) tri4 and tri5 genes amplified from $4 \mathrm{~F}$ and $9 \mathrm{~F}$ isolates. (B) $0.7 \mathrm{~kb}$ hph fragment obtained from fungal isolates' genomic DNAs transfected by siRNAand pAN 7-1. M1: 100 bp DNAladder (Thermo, U.S.A.), M2: 1 kb DNAladder(Thermo, U.S.A.), N: No template.

Full length amplicons were cloned into pGEM-T Easy vector. The nucleotide sequences of tri4 belonging to $4 \mathrm{~F}, 9 \mathrm{~F}$ and $20 \mathrm{~F}$ isolates were registered in the GenBank with accession numbers KJ677970, KJ677971 and Kj677972. Similarly, KJ677973, KJ677974 and KJ677975 accession numbers were given for tri5 gene belonging to $4 \mathrm{~F}, 9 \mathrm{~F}$ and $20 \mathrm{~F}$ isolates, respectively, by GenBank. After sequencing, the tri4 and tri5 sequences were converted to amino acid data and then aligned. It was revealed in BlastP analysis that the variations found in tri4 and tri5 genes belonged to both reference strain (F. graminearum NRRL 28336) and all isolates used in this study were responsible for 25 and 16 amino acid differences (Fig. 2).

At least 10 potential regions covering exon sequences of each gene were detected for siRNA designing. After selection of DNA regions with a maximum of $100 \%$ identity, a total of 6 doublestranded siRNAs were designed, with 4 for tri4 and 2 for tri5 (Table 1). Protoplasts ranging from $1 \times 10^{5}$ to $5 \times 10^{6}$ were obtained from mycelia by treatment with lytic enzyme for 5-6 hrs. Putative 4F, 9F and 20F transformants were detected on selective PDB medium containing
$25 \mathrm{\mu g} \mathrm{ml}^{-1}$. siRNA transfection was indirectly confirmed by PCR amplification of $0.7 \mathrm{~kb}$ DNA fragments belonging to hph gene (Fig. 2B). It was observed that all isolates were successfully transfected with pEGFP75 at different siRNA combinations. Additionally, RFU values of fungal isolates transfected with siRNA and pEGFP75 plasmid were normalized as comparised to no-transfected control groups. Minimum RFU value of 1.37 was recorded in $20 \mathrm{~F}$ transfected with triple siRNA (siRNA4E1+ siRNA4E2+siRNA4E3). However, maximum RFU value was calculated as 2.89 in 4F with double siRNA transfected (siRNA4E2+siRNA4E3). In variance analysis, RFU value of each experiment set showed significant difference in comparison to control groups (Fig. 3 A-B) according to Tukey's post hoc-test ( $p<0.001$ ). In addition, protoplast-based transfection frequencies ranged from $50 \pm 0.0 / 5 \times 104$ to $99.33 \pm 10.06 / 5 \times 10^{4}$.

In total, 30 tri4 specific siRNA transfected experiment sets and non-transfected fungal groups were subjected to gene expression analysis. No tri4 expression ( $\Delta \Delta C \mathrm{CT}$ values of 0.00 ) was recorded in all running samples in Taq-Man probe-based qPCR analysis. Tri4 gene was totally silenced in different siRNA

Table 1 : siRNA specific to tri4 and tri5 genes

\begin{tabular}{lllll}
\hline siRNA & Target & Exon & Sequence (5'-3') & Size(bp) \\
\hline RNAi41 & tri4 & 1 & ACAATACGGGCGTGAGTCATGTCAA & 25 \\
sRNAi42 & tri4 & 2 & GAACCCTGAGAGAAGTTGGTGATGT & 25 \\
sRNAi43 & tri4 & 3 & ACATGCTCCTTGTACTTCAAGTTCT & 25 \\
sRNAi44 & tri4 & 4 & CATCTTGGAGATCTCCCAGAGAT & 23 \\
siRNAi51 & tri5 & 1 & AAGCGACTACAGGCTTCCCTCCAAA & 25 \\
sRNAi52 & tri5 & 2 & CAGGATCTGATGACTACCCTCAATT & 25 \\
\hline
\end{tabular}




\begin{tabular}{|c|c|}
\hline $9 \mathrm{~F}$ & YTREERIENLHYAYNKAAHHFAQPRQQQMLKVDPKRLQASLQTIVGMVVYSWAKVSKECM \\
\hline $20 \mathrm{~F}$ & YTREERIENLHYAYNKAAHHFAQPRQQQMLKVDPKRLQASLQTIVGMVVYSWAKVSKECM \\
\hline Reference & YTREERIENLHYAYNKAAHHFAQPRQQQMLKVDPKRLQASLQTIVGMVVYSWAKVSKECM \\
\hline $4 \mathrm{~F}$ & 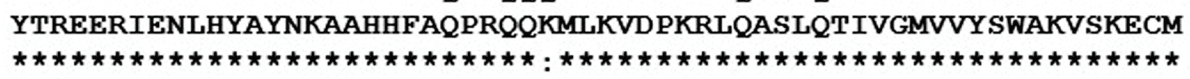 \\
\hline $9 \mathrm{~F}$ & ADLSIHYTYTLVLDDSSDDPHPAMLNYFDDLQAGREQSHPWWALVNEHFPNVLRHFGPFC \\
\hline $20 \mathrm{~F}$ & ADLSIHYTYTLVLDDSSDDPHPAMLNYFDDLQAGREQSHPWWALVNEHFPNVLRHFGPFC \\
\hline Reference & ADLSIHYTYTLVLDDSSDDPHPAMLNYFDDLQAGREQSHPWWALVNEHF PNVLRHFGPFC \\
\hline $4 \mathrm{~F}$ & 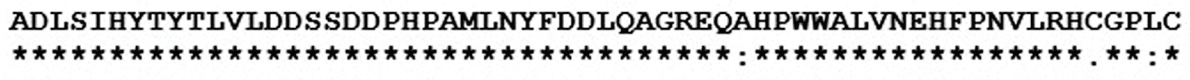 \\
\hline $9 \mathrm{~F}$ & SLNLIRSTMDFFEGCWIEQYNFGGF PGSDDYPQFLRRMNGLGHCVGASLWPKDLFDERKN \\
\hline $20 \mathrm{~F}$ & SLNLIRSTMDFFEGCWIEQYNFGGF PGSDDYPQFLRRMNGLGHCVGASLWPKDLFDERKN \\
\hline Reference & SLNLIRSTMDFFEGCWIEQYNFGGFPGSDDYPQFLRRMNGLGHCVGASLWPKDLFDERKN \\
\hline $4 \mathrm{~F}$ & 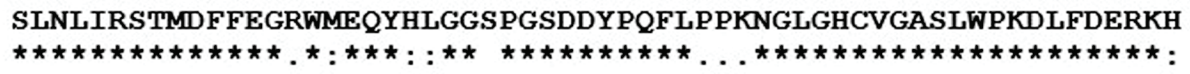 \\
\hline $9 \mathrm{~F}$ & FLEITTAVAQMENWMVWVNDLMSFYKEFDDERDQISLVKNFVTCHKITLDEALEKLTQET \\
\hline $20 \mathrm{~F}$ & FLEITTAVAQMENWMVWVNDLMSFYKEFDDERDQISLVKNFVTCHKITLDEALEKLTQET \\
\hline Reference & FLEITTAVAQMENWMVWVNDLMSFYKEFDDERDQISLVKNFVTCHEITLDEALEKLTQET \\
\hline $4 \mathrm{~F}$ & 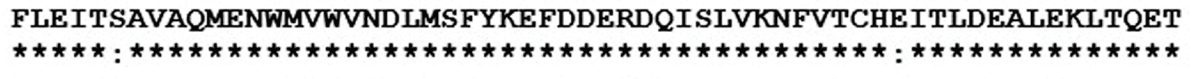 \\
\hline $9 \mathrm{~F}$ & LHSSKQMVAVFADKDPQVMDTIECFMHGYVTWHLCDARYRLHEIYEKVKDQDTEDAKKFC \\
\hline $20 \mathrm{~F}$ & LHSSKQMVAVFADKDPQVMDTIECFMHGYVTWHLCDARYRLHEIYEKVKDQDTEDAKKFC \\
\hline Reference & LHSSKQMVAVFADKDPQVMDTIECFMHGYVTWHLCDARYRLHEIYEKVKDQDTEDAKKFC \\
\hline $4 \mathrm{~F}$ & 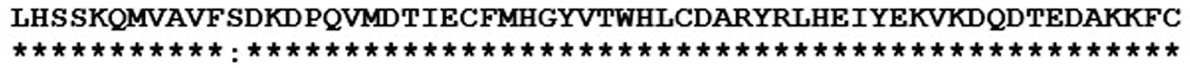 \\
\hline
\end{tabular}

Fig.2 : BlastP analysis of trichodiene synthase protein encoded by partial region of tri5 gene. '*' indicates conserved amino acids while '.' and ':'mean mutations in amino acids sequences.

combinations. qPCR was also carried out in 6 experimental sets transfected with tri5 specific siRNAs. $\triangle \mathrm{CT}$ values for siRNA treated isolates and control sets were calculated as 2.68-5.72 and $-1.82-0.71$, respectively. $\Sigma \Delta \Delta$ CT values ranged from 1.97 to 7.54 (Table 2). The effects of pEGFP75 used in co-transfection to transfection efficiency was tested by scramble set (including helper plasmid transfection). Down-regulation for tri5 gene was recorded ranging from 74.5 to $99 \%$ according to $2^{-\triangle \Delta C T}$ formula. Significant differences $(p<0.005)$ were not detected between the gene expression levels and increased number of siRNAs. Therefore, no correlation was found among them. Moreover, RTPCR analysis supported the findings from qPCR assays (data not shown). The housekeeping gene amplicons were detected in each set. While control sets showed tri4 and tri5 RT-PCR bands on agarose gels, siRNA-transfected sets showed no bands on gels. Quelling was verified by TLC. No spots corresponding to DON was yielded from tri4 and tri5 silenced isolates in silica gels. However, control sets showed spots with Rf value of 0.28 (data not shown). Fusarium spp. including $F$. graminearum and $F$. culmorum cause devastating diseases worldwide and epidemics leading to significant yield and economic loses and mycotoxin contamination in foods (Matny, 2015). Additionally, stable (in food processing phase) mycotoxin molecules produced by $F$. graminearum and F. culmorumare also causative agents for animals and humans (Desjardins and Proctor, 2007). siRNA based quelling strategy was performed for inhibition of trichothecene production. For this purpose, tri4 and tri5 genes encoded proteins which are essential in trichothecene biosynthesis

Table 2 : Fold changes in tri5 gene expression analysis in tri5 specific siRNA transfected and positive control isolates

\begin{tabular}{|c|c|c|c|c|c|}
\hline Isolate & siRNA & $\Sigma \Delta \mathrm{CT}$ (treated) & $\Sigma \Delta \mathrm{CT}$ (untreated) & $\Sigma \Delta \Delta \mathrm{CT}$ & $\begin{array}{l}2-\Delta \Delta C T / \\
\text { Downregulation }\end{array}$ \\
\hline $4 \mathrm{~F}$ & sRNAi51 & $2.68 \pm 0.79$ & $0.71 \pm 0.14$ & $1.97 \pm 0.65$ & 0.255 \\
\hline $4 \mathrm{~F}$ & siRNA52 & $4.89 \pm 0.85$ & $0.71 \pm 0.14$ & $4.18 \pm 0.71$ & 0.055 \\
\hline $4 \mathrm{~F}$ & siRNA51+52 & $5.23 \pm 0.15$ & $0.71 \pm 0.14$ & $4.52 \pm 0.14$ & 0.043 \\
\hline $9 F$ & sRNAi51 & $5.64 \pm 0.57$ & $-1.82 \pm 0.13$ & $7.46 \pm 0.7$ & 0.056 \\
\hline $9 F$ & siRNA52 & $5.72 \pm 0.03$ & $-1.82 \pm 0.13$ & $7.54 \pm 0.8$ & 0.05 \\
\hline $9 F$ & siRNA51+52 & $3.23 \pm 0.9$ & $-1.82 \pm 0.13$ & $5.05 \pm 0.52$ & 0.03 \\
\hline
\end{tabular}




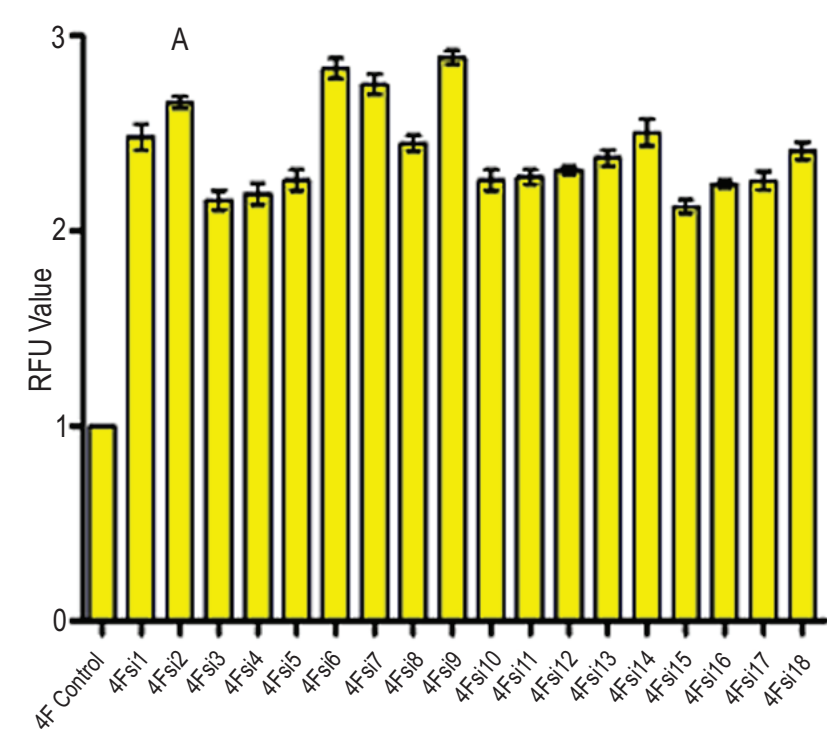

Fusarium graminearum 4F Isolate

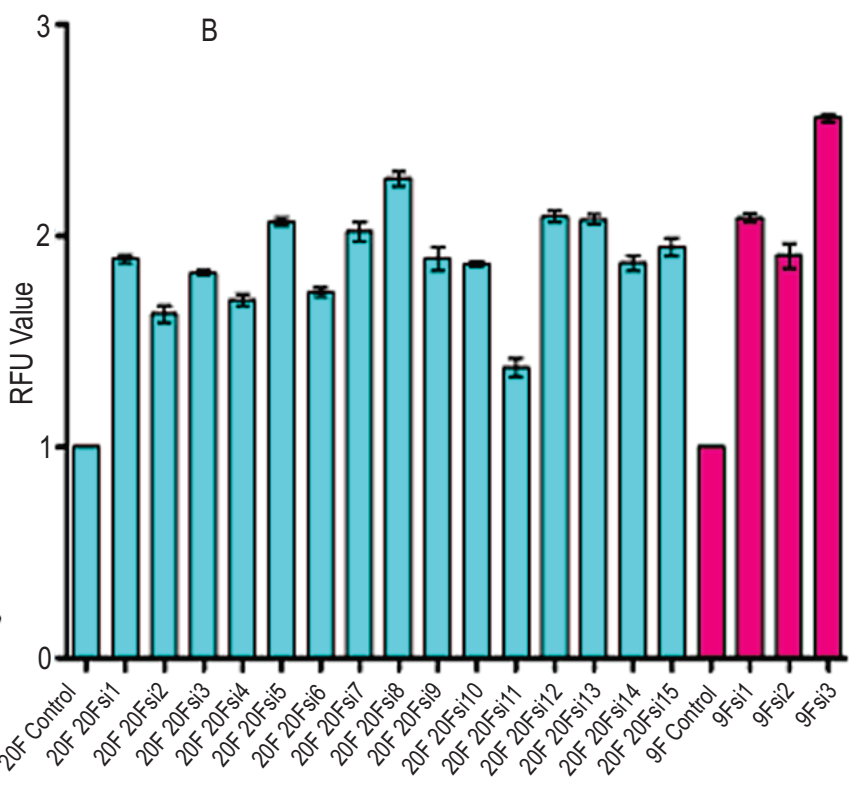

Fusarium culmorum (20F and $9 \mathrm{~F})$ isolates

Fig. 3: One-way ANOVA profiles of spectro fluorimetric values belonging to transfectants of (A) F. graminearum 4F; (B) F. culmorum 20F and $9 \mathrm{~F}$ isolates.

were targeted to silence of DON. Both genes have not been used before in trichothecene quelling. At first, high level of DON producing isolates, in vitro culture conditions among 38 isolates, were selected without plant-microbe interaction by using qPCR analysis. Amplification based chemotyping confidently provided data about mycotoxin profiling in a short time. At the same time, DON production was verified with TLC. PCR applications are effectively used for quantitation of endotoxins commonly detected with sophisticated analytic techniques because microarray is not commercially available (Güldener et al., 2006; Pinson-Gadais et al., 2008; Merhej et al., 2010). Tri4 and tri5 specific siRNA mediated quelling was developed in this study.

The tri6 gene, which encodes transcription factor for tri5 gene cluster, have been subjected to vector based genetic manipulation studies to inhibit trichothecenes biosynthesis (McDonald et al., 2005; Scherm et al., 2011). As in this study, gfp and/ or hph based verification systems were used in tri6 quelling studies. However, tri6 does not include intronic regions whereas both genes used in this study contain at least one intron. The tri6 silencing studies resulted in down regulation of tri6 and decrease in trichothecene production. Product encoded by tri6 is a zinc finger transcription factor, and other general transcription factors replace it in the absence of TRI6 protein in the cell. However, Scherm et al. (2011) reported that tri6 quelling in some experimental sets dramatically led to up regulation and/or increase in toxin production. Even if vector-based quelling provides development of stable silenced strains for generations, positive selection of these strains or isolates in population will be time-consuming in disease management. Therefore, novel strategies have to be developed for quelling of Fusarium mycotoxins. Since siRNA-based quelling offers an alternative approach, Barnes et al. (2008) used siRNA delivery to protoplasts of Aspergillus niger. They successfully obtained down-regulated specific genes (uidA and GUS) in the species. But, they determined that RNA interference mechanism resulted in transient quelling instead of stable gene silencing. The siRNA transfection targeted to genes associated with mycotoxin production provided a powerful approach, in this study. Tri4 expression was totally quelled in siRNA delivered Fusarium isolates. Similarly, tri5 gene was also silenced up to $99 \%$ with siRNA. Both real-time PCR assay and TLC analysis showed absence of $D O N$ production.

Lyposome based quelling may provide a powerful tool in struggling with diseases. This study revealed that tri4 and tri5 genes can be targeted in the development of less DON-producing strains through RNAi in F. graminearum and F. culmorum. Although siRNA transfection lead to transient quelling, it was shown that the highest level of down-regulation could be obtained from this study.

\section{Acknowledgments}

The study was supported by Research Fund of Istanbul University by project number 23489 . Authors are grateful to Dr. B. Tunali for providing fungal material and Dr. P.J. Punt and Dr. H. Nakayashiki for plasmids. 


\section{References}

Barnes, S.E., M.J.C. Alcocer and D.B. Archer: siRNA as a molecular tool for use in Aspergillus niger. Biotech. Lett., 30, 885-890 (2008).

Battilani, P., C. Barbano. and A. Logrieco: Risk assessment and safety evaluation of mycotoxins in fruits. In: Mycotoxins in fruit and vegetables (Eds.: R. Barkai-Golan and N. Paster). Wageningen Academic Press, U.S.A., pp. 1-26 (2008).

Brown, D.W., R.B. Dyer, S.P. McCormick, D.F. R.D. Kendra and Plattner: Functional demarcation of the Fusarium core trichothecene gene cluster. Fungal Genet. Biol., 41, 454-462 (2004).

Desjardins, A.E. and R. H. Proctor: Molecular Biology of Fusarium mycotoxins. Int. J. Food Microbiol., 119, 47-50 (2007).

Doyle, J.J. and J.L. Doyle: A rapid DNA isolation procedure for small quantities of fresh leaf tissue. Phytochem. Bull., 19, 11-15 (1987).

Güldener, U., K.Y. Seong, J. Boddu, S. Cho, F. Trail, J.R. Xu, G. Adam, H.W. Mewes, G.J. Muehlbauer and H.C. Kistler: Development of a Fusarium graminearum affymetrix gene chip for profiling fungal gene expression in vitro and in planta. Fungal Genet. Biol., 43, 316-325 (2006).

Kang, Z., L. Huang, U. Krieg, M.A. Machnik and H. Buchenauer: Effects of tebuconazole on morphology, structure, cell wall components and trichothecene production of Fusarium culmorum in vitro. Pest Manag. Sci., 57, 491-500 (2001).

Kimura, M., T. Tokai, N. Takahashi-Ando, S. Ohsato and M. Fujimura: Molecular and genetic studies of Fusarium trichothecene pathways gene and evolution. Biosci. Biotechnol. Biochem., 71, 2105-2123 (2007).

Kuiper-Goodman, T.: Risk assessment and risk management of mycotoxins in food. In: Mycotoxins in Food Detection and Control (Eds.: N. Magan and M. Olsen). CRC Press, England, pp. 1-27 (2004).
Leeja, L. and J. E. Thoppil: Antimicrobial activity of methanol extract of Origanum majorana L. (Sweet marjoram). J. Environ. Biol., 28, 145-146 (2007).

Livak, J. K. and T. D. Schmittgen: Analysis of relative gene expression data using real time quantitative PCR and the $2^{-\triangle \triangle C T}$ method. Methods, 25, 402-408 (2001).

Matny, O.N.: Fusarium head blight and crown rot on wheat and barley: Losses and health risks. Adv. Plants Agric. Res., 2, 1-6 (2015).

McDonald, T., D. Brown, N.P. Keller and T.M. Hammond: RNA silencing of mycotoxin production in Aspergillus and Fusarium species. Mol. Plant Microbe Interact., 18, 539-545 (2005).

Merhej, J., A.L. Boutigny, L. Pinson-Gadais, F. Richard-Forget and C. Barreau: Acidic $\mathrm{pH}$ as a determinant of TRI gene expression and trichothecene B biosynthesis in Fusarium graminearum. Food Addit. Contam., 27, 710-717 (2010).

Nakayashiki, H. and Q.B. Nguyen: RNA interference: Roles in fungal biology. Curr. Opin. Microbiol., 11, 494-502 (2008).

Pinson-Gadais, L., F. Richard-Forget, P. Frasse, C. Barreau, B. Cahagnier, D. Richard-Molard and B. Bakan: Magnesium represses trichothecene biosynthesis and modulates Tri5, Tri6 and Tri12 genes expression in Fusarium graminearum. Mycopathologia, 165, 51-59 (2008).

Ruvkun, G.: Glimpses of a tiny RNAworld. Science, 294, 797-799 (2001).

Scherm, B., M. Orru, V. Balmas, F. Spanu, E. Azara, G. Delogu, T.M. Hammond, N.P. Keller and Q. Migheli: Altered trichothecene biosynthesis in TRI6-silenced transformants of Fusarium culmorum influences the severity of crown and foot rot on durum wheat seedlings. Mol. Plant Pathol., 12, 759-771 (2011).

Sobrova, P., V. Adam, A. Vasatkova, M. Beklova, L. Zeman and R. Kizek: Deoxynivalenol and its toxicity. Interdisc. Toxicol., 3, 94-99 (2010).

Thakur, A.: RNA interference revolution. Electron. J. Biotechnol., 6, 3949 (2003). 